\title{
Vitreous opacities in primary amyloid disease A clinical, histochemical, and ultrastructural report
}

\author{
ROGER A. HITCHINGS AND RAMESH C. TRIPATHI* \\ Moorfields Eye Hospital and Department of Pathology, \\ Institute of Ophthalmology (University of London)
}

Severe loss of visual acuity due to vitreous opacities may result from haemorrhages, inflammatory and degenerative conditions, tumour cells, or amyloidthe last being rare (Duke-Elder, I969; Jaffe, I 969). It is important, however, to recognize amyloid disease as being a cause of vitreous opacities, because most previously reported cases have been patients with familial amyloidosis, a systemic disease of protean manifestations with a poor prognosis. Sporadic cases of systemic amyloidosis with vitreous opacities have also been reported (see Table).

Patients with systemic amyloid disease may initially present with visual symptoms due to vitreous opacities. These opacities usually have a characteristic appearance thus enabling the ophthalmologist to suggest the correct diagnosis.

The purpose of this paper is to report three patients of primary amyloid disease, who initially presented to the ophthalmologist with slow deterioration of their visual acuity. The diagnosis was suggested by the appearance of the vitreous opacities and confirmed initially by conjunctival biopsy in two of the three cases and subsequently by histological examination of the vitreous in all three cases. To our knowledge, this is the first British report of vitreous opacities in primary amyloid disease.

\section{Case reports}

\section{CASE I}

A 53-year-old Caucasian woman initially presented at another hospital in December 1970 with a history of progressive loss of visual acuity during seven years in her right and five years in her left eye. There was no history of systemic or ocular disease, nor were her visual symptoms precipitated by trauma. There was no relevant family history of ocular or systemic illness. At that hospital she underwent an extracapsular lens extraction and partial vitrectomy in her right eye.

On examination at Moorfields Eye Hospital in January $197 \mathrm{I}$, her visual acuity in the right eye was percep-

*Address for reprints: R. C. Tripathi, $\mathrm{MD}, \mathrm{PhD}$, Institute of Ophthalmology, Judd Street, London WCiH $9 \mathrm{QS}$ tion of light, and in the left eye hand movements. The right eye showed evidence of a broad iridectomy and an extracapsular lens extraction. The posterior vitreous was opaque. The left eye had a normal anterior segment with a clear lens. On the posterior lens surface there were multiple white circumscribed opacities in the form of 'pseudopodia lentis'; from each opacity an opaque strand could be traced posteriorly, through a region of clear vitreous, to enter a greyish-white meshwork of vitreous opacities (Figs I and 2). No view of the fundus could be obtained in either eye.

The following investigations were carried out: chest $x$ ray, haemoglobin (Hb), white blood count (WBC), erythrocyte sedimentation rate (ESR), electro-oculogram (EOG) and electroretinography (ERG)-all of which were within normal limits. Electrophoresis of serum proteins, however, revealed an elevated $\alpha_{2}$ globulin.

In January 1971, a right vitrectomy by the 'open sky' technique (Kasner, Miller, Taylor, Lever, and Norton, I968) was performed. Subsequent examination of the fundus failed to reveal any abnormality. One month later the retina totally detached and remained so, despite attempts at surgical management; the eye subsequently became phthisical. In January I972, prophylactic encircling cryotherapy was carried out on the peripheral retina of the left eye. A diagnostic conjunctival biopsy was performed for histopathological and electron microscopical examination. In March 1972, a left vitrectomy was performed, again using the 'open sky' technique and the material was processed for light and electron microscopical examinations. Postoperatively, as far as the fundus could be seen, it appeared to be normal. However, it became obscured by an increase in the vitreous opacities during the next 4-6 weeks and was followed by a gradual onset of bullous keratopathy.

After ophthalmological examination and conjunctival biopsy, the patient was referred for a general medical examination which revealed a peripheral neuropathy and carpal tunnel syndrome, attributable to systemic amyloid disease.

It has not proved possible to examine other members of the family.

\section{CASE 2}

A 54-year-old Caucasian man presented with a royear history of progressive bilateral loss of visual acuity. In September 1971, he was admitted to another 

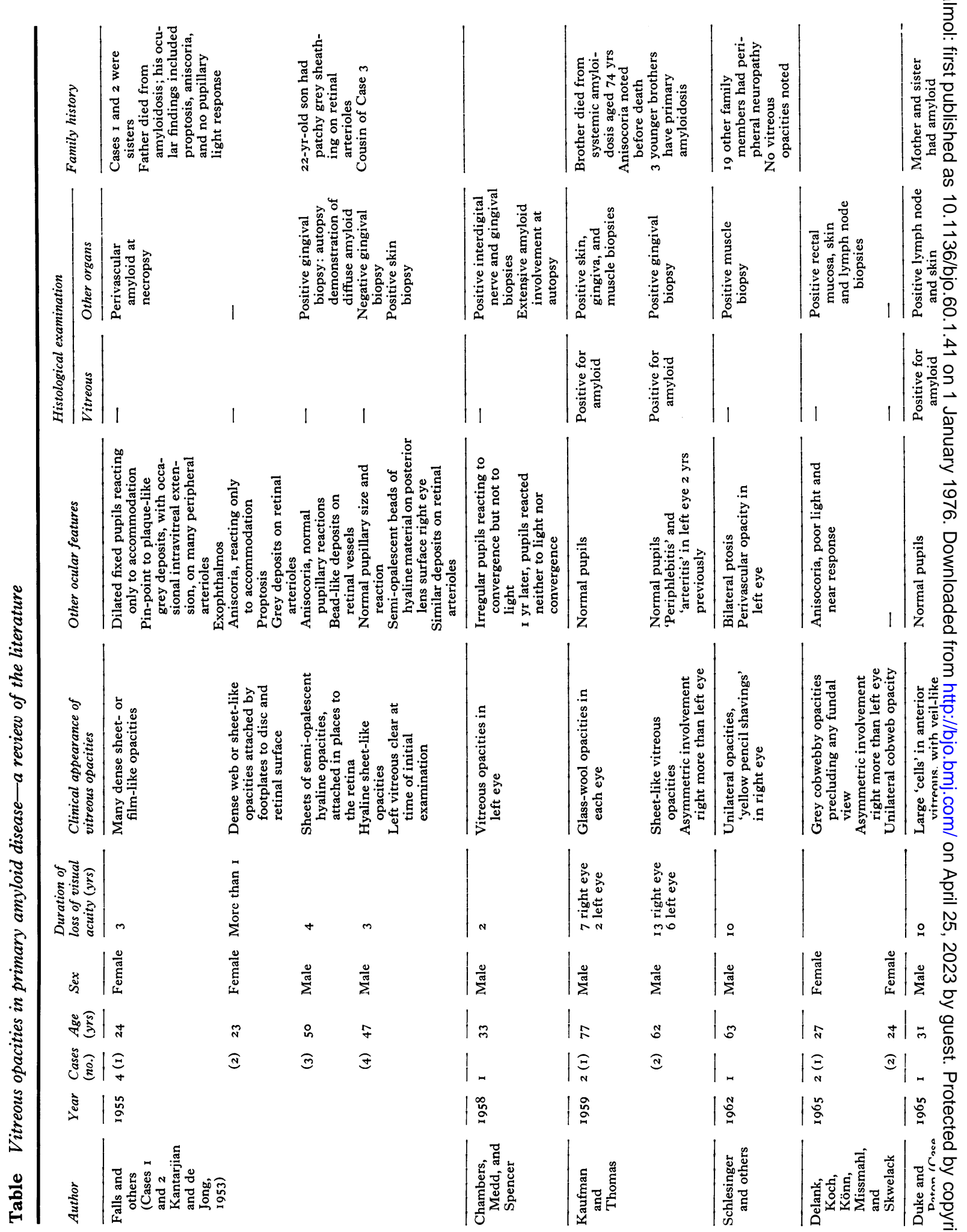

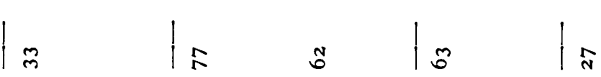
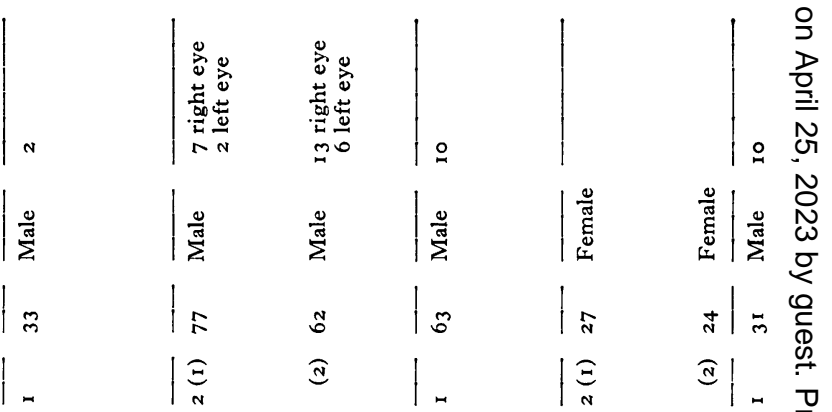

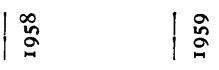

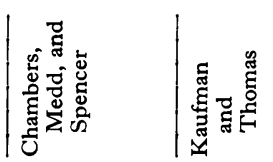

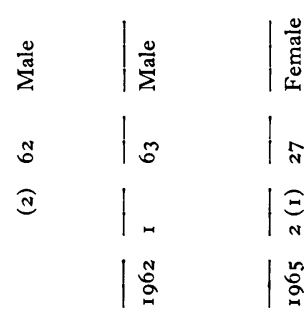

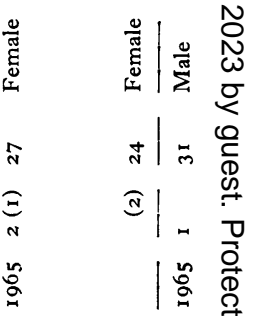

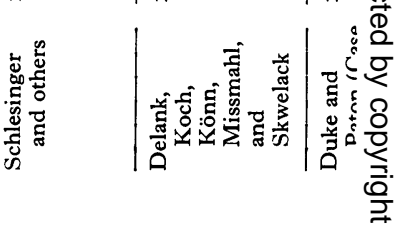



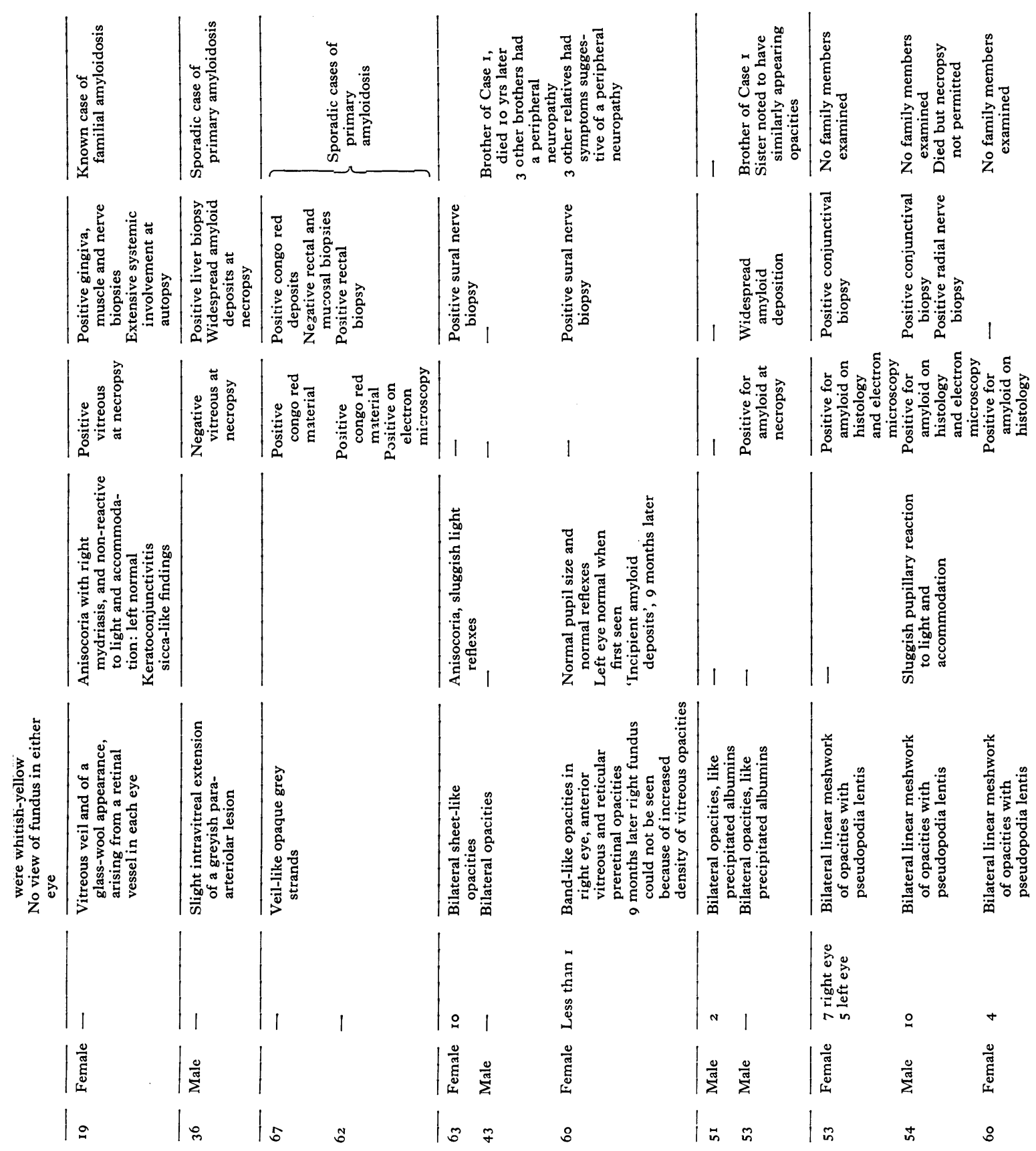

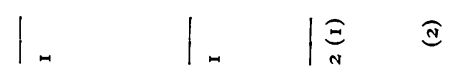

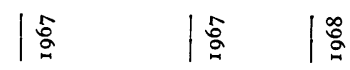

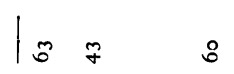

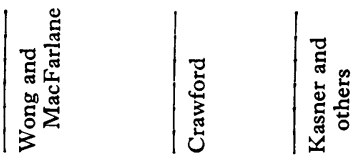
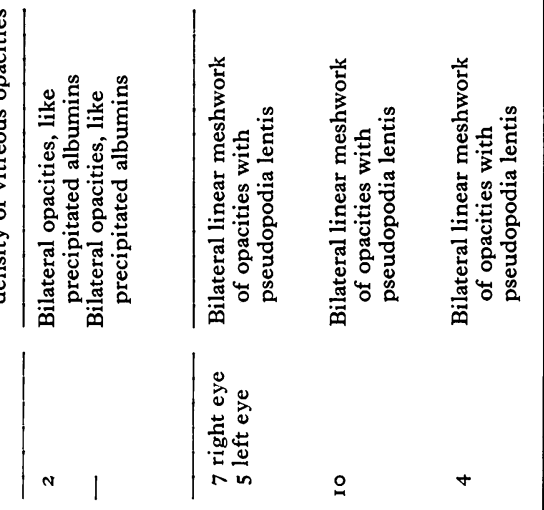

| in in $\mid$ in it

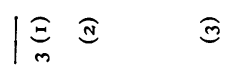

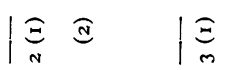

ิㅡ

1:

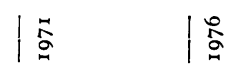
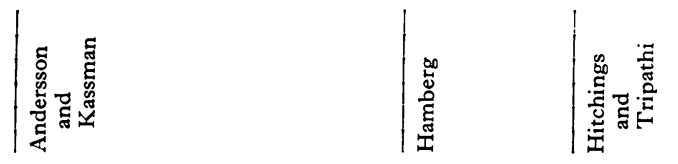


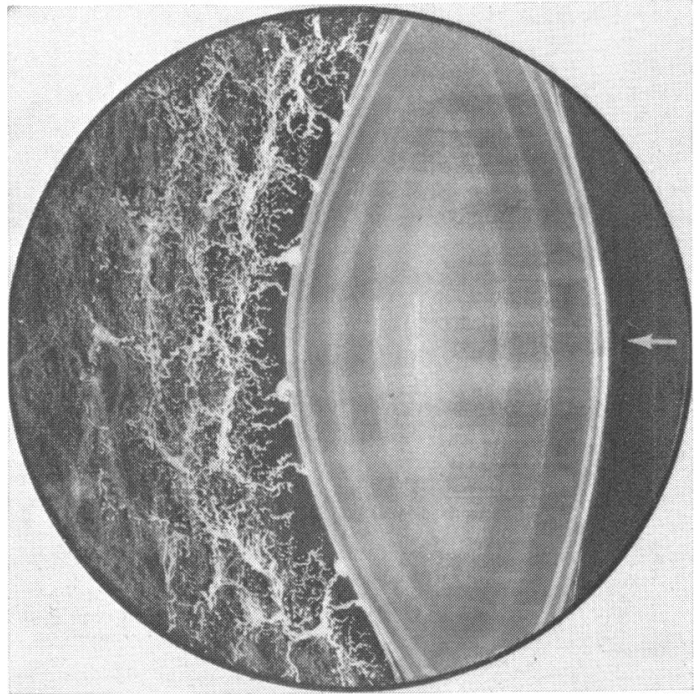

FIG. I Case I. Left eye. Artist's impression showing meshwork of linear vitreous opacities attached to posterior lens surface by footplates (pseudopodia lentis) hospital for investigation where his visual acuity was recorded as 6/24 right eye and counting fingers left; bilateral vitreous opacities were noted. Examination of the fundus in the right eye showed no abnormality, but the fundus could not be seen in the left eye. Neither he nor his family had any history of ocular or medical disease. Further loss of visual acuity occurred and he was transferred to Moorfields Eye Hospital in February 1972.

On examination, his visual acuity was $6 / 60$ right eye, counting fingers left. His visual fields were full to a $10 \mathrm{~mm}$ white target. The ERG and EOG did not reveal any abnormality. Each anterior segment was normal. The pupils were equal in size but with sluggish light and near reactions. The intraocular pressures were normal. The lens in each eye was clear but there were multiple circumscribed greyish-white opacities on the posterior surface of each lens (Figs 3 and 4 ) and from each opacity an opaque fibril ran posteriorly, through a relatively clear zone, to join a meshwork of vitreous opacities. No view of either fundus was possible. Amyloid disease was suspected and although the conjunctiva appeared to be normal, a diagnostic conjunctival biopsy was performed.

The patient was referred for a general medical examination which revealed a peripheral neuropathy,

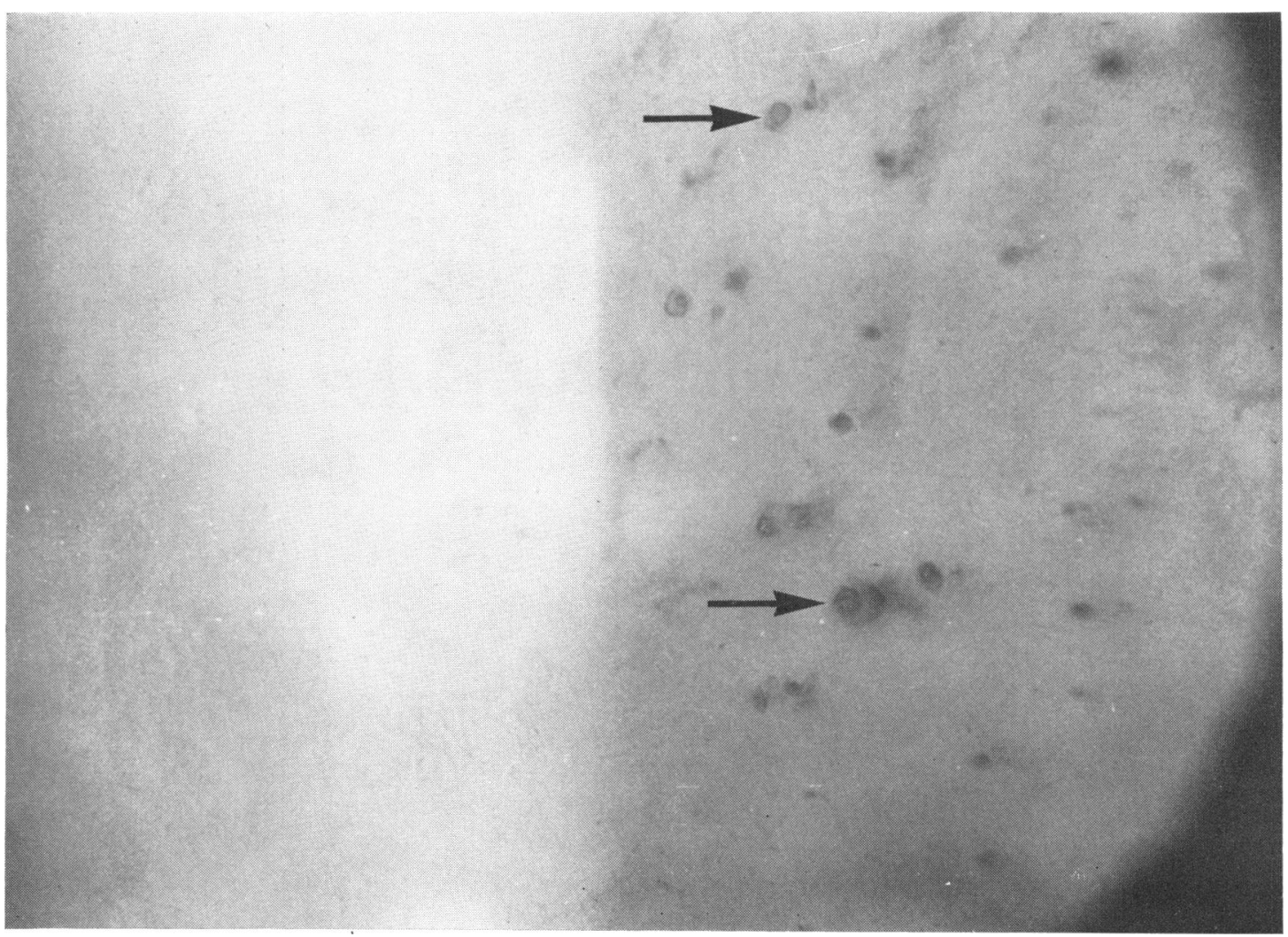

FIG. 2 Case 1. Left eye. Slit-lamp photograph of lens focused on posterior lens surface, demonstrating footplate attachments, pseudopodia lentis (arrow), of vitreous opacities 
orthostatic hypotension, and an abnormal sweating pattern. Biopsy of the left superficial radial nerve was performed which showed perineural deposits of amyloid together with degenerative changes in the nerve fibres. No abnormality, however, was detected on chest $x$-ray examination; blood analysis for $\mathrm{Hb}, \mathrm{WBC}, \mathrm{ESR}$, and serum proteins was also normal. There was no BenceJones protein in the urine.

In September 1972, the patient underwent prophylactic encircling peripheral retinal cryotherapy followed by an 'open sky' vitrectomy (Kasner and others, I 968) to the right eye 2 months later. The vitreous material thus being available was examined by light and electron microscopy. In July 1973 he underwent a $6.5 \mathrm{~mm}$ penetrating keratoplasty for bullous keratopathy. Histopathological examination of the corneal disc revealed features of Fuchs's dystrophy but no deposits of amyloid.

In September 1973 he developed renal failure and despite intensive care he died. Permission for necropsy examination was not given.

It has not proved possible to examine other members of his family.

\section{CASE 3}

A 60-year-old Caucasian woman presented in 1967 with a 12 month history of 'cobwebs' in front of both eyes. At that time she was being treated for low blood pressure. The features of her vitreous opacities have been reported elsewhere (Law, I97I). Neither she nor her family had any history of ocular or systemic disease.

On examination, her visual acuity was $6 / 9$ right eye and $6 / 6$ left. The anterior segments and intraocular pressure were normal in each eye. The lens in each eye was clear. Multiple circumscribed white opacities were, however, present on the posterior surface of each lens

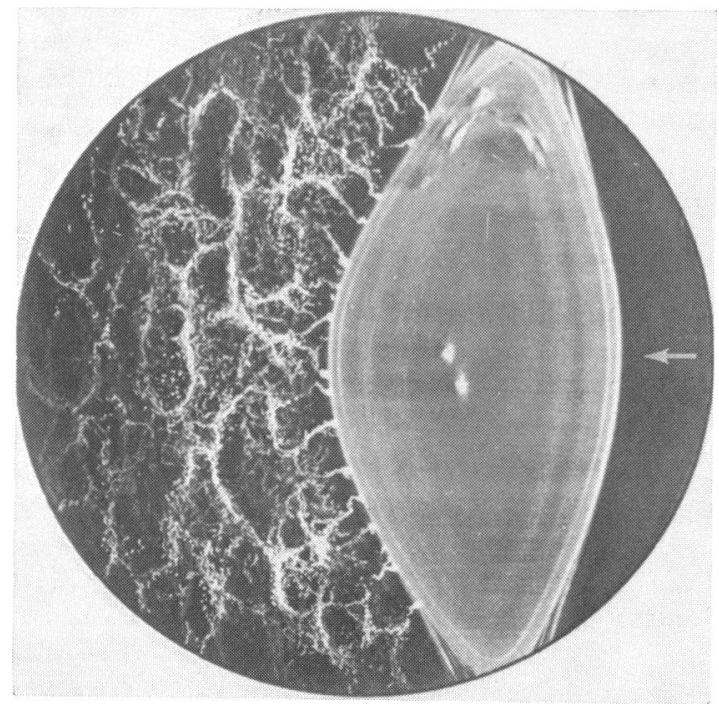

FIG. 3 Case 2. Left eye. Artist's impression showing a meshwork of linear opacities attached to posterior lens surface by footplates (pseudopodia lentis)

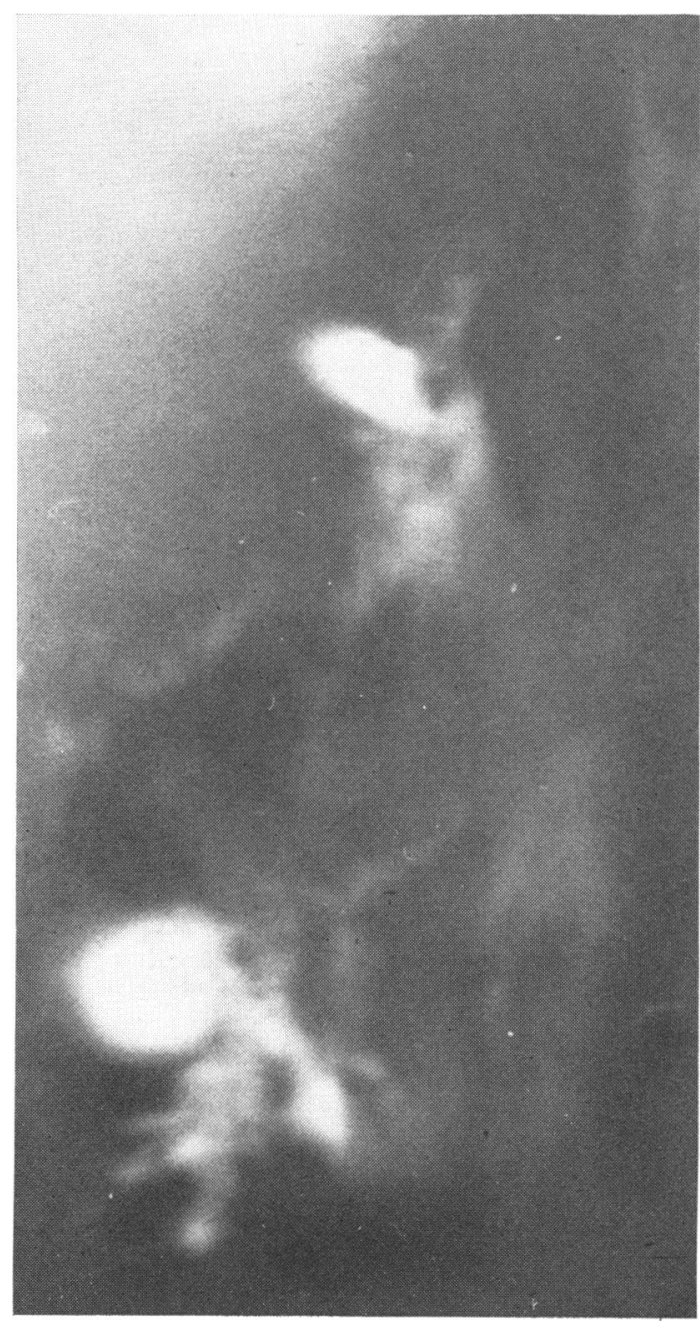

FIG. 4 Case 2. Left eye. Macrophotograph showing two 'footplate' vitreous opacities on posterior lens surface, each with linear vitreous opacities passing posteriorly into vitreous cavity

and from these greyish-white fibrillar opacities extended posteriorly to join an extensive meshwork of opacities in the central vitreous (Fig. 5). No fundal abnormality could be detected in either eye.

Because of bilateral loss of visual acuity, several months later she attended another hospital and underwent bilateral vitrectomy; a diagnosis of amyloidosis of the vitreous was made.

\section{Histopathology and ultrastructure}

Conjunctival biopsies (ro $\times 8 \mathrm{~mm}$ ) were obtained from the lower fornix (Cases I and 2) under local amethocaine anaesthesia. The specimens were divided into two pieces; one piece of each specimen, intended for conventional light microscopy and 


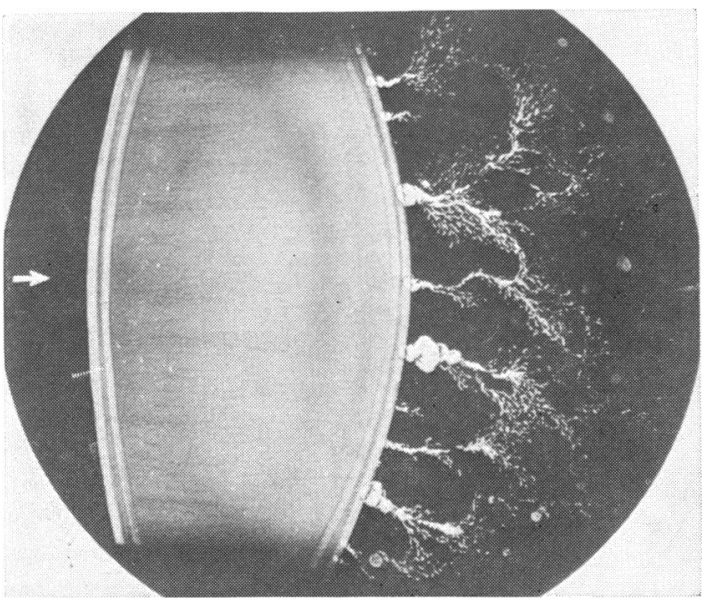

FIG. 5 Case 3. Left eye. Artist's impression showing linear vitreous opacities attached to posterior lens surface by footplates (pseudopodia lentis)

histochemical studies, was fixed in formol saline and embedded in paraffin wax; sections were stained with haematoxylin and eosin, congo red, periodic acid-Schiff, crystal violet, toluidine blue, and thioflavine $T$. The other piece of each specimen was fixed in veronal acetate buffered osmium tetroxide, dehydrated through ascending grades of ethanol, and was finally embedded in Araldite. Sections were cut with glass knives on a LKB ultramicrotome; semi-thick sections ( $\mathrm{I} \mu \mathrm{m}$ ) were stained with toluidine blue for block orientation and examination by light microscopy. Thin sections $(70-90 \mathrm{~nm})$ were stained with uranyl acetate (alcoholic or aqueous) and aqueous lead citrate, and electron micrographs were taken using AEI EM6 and Joel 10oC electron microscopes.

Similarly, vitreous specimens taken at the time of vitrectomy from both cases, were processed for conventional histological examination and electron microscopy. Some vitreous material was also spread directly on glass slides as a smear and this was stained with haematoxylin and eosin, congo red, crystal violet, and thioflavine $\mathrm{T}$.

The lens from Case I was fixed in formol saline, embedded in celloidine and sections were stained for light microscopy as described for the conjunctival specimens. The posterior half of the lens from Case 2 was dissected out, and the tissue blocks were fixed in osmium tetroxide and processed for electron microscopy.

\section{CONJUNCTIVA}

\section{Light microscopy and histochemistry}

An amorphous, eosinophilic, hyaline extracellular material was seen around the vessels, particularly around the veins and lymphatics (Fig. 6). In Case 2, the deposits were also seen immediately beneath the conjunctival epithelium. The deposits stained positively with periodic acid-Schiff and congo red, metachromatically with crystal violet, and khaki colour with van Gieson; to some extent they were autofluorescent but this was greatly enhanced after staining with thioflavine $\mathrm{T}$ (Fig. 7). When viewed by polarized light, the congo red positive material showed birefringency and green dichroism, These histochemical findings are characteristic of amyloid (Missmahl, 1957; Vassar and Culling, I959; Puchtler, Sweat, and Levene, r962; Cooper, 1969; Pearse, 1972; and others).

\section{Ultrastructure}

Electron microscopy generally confirmed the location of the amyloid material seen by light microscopy (Figs 8 and 9). The deposits were variably sized clumps of fine, interlacing, non-branching fibrils. In uranyl acetate and lead citrate stained sections, the individual fibrils were 7-10 $\mathrm{nm}$ in diameter; longitudinally-cut fibrils showed two laterally-aligned filaments approximately $3 \mathrm{~nm}$ in diameter with an intervening space of approximately $3 \mathrm{~nm}$. The filaments had a beaded appearance repeating at approximately $4 \mathrm{~nm}$. These features are consistent with the electron microscopical appearance of amyloid (Boeré, Ruinen, and Scholten, 1965; Shirahama and Cohen, 1965, 1967; Gueft, Kikkawa, and Hirschl, I968; Sorenson and Finke, 1968; and others). The ground substance was relatively electron lucent.

In Case 2 wherein subepithelial deposits were seen, the basement membrane was intact and there was no infiltration of the amyloid material into the epithelium.

\section{VITREOUS}

\section{Light microscopy and histochemistry}

Smears and sections of the vitreous from Cases I and 2 showed fine and coarse meshworks which stained positively with periodic acid-Schiff and congo red, and metachromatically with crystal violet. Under polarized light, haematoxylin and eosin sections showed birefringency and congo red stained sections additionally showed a green dichroism (Figs Ioa and b). The vitreous material from Case 3 was also reported as showing histochemical features of amyloid deposits.

\section{Ultrastructure}

Thin sections of the vitreous opacities from Cases I and 2 stained with uranyl acetate and lead citrate 


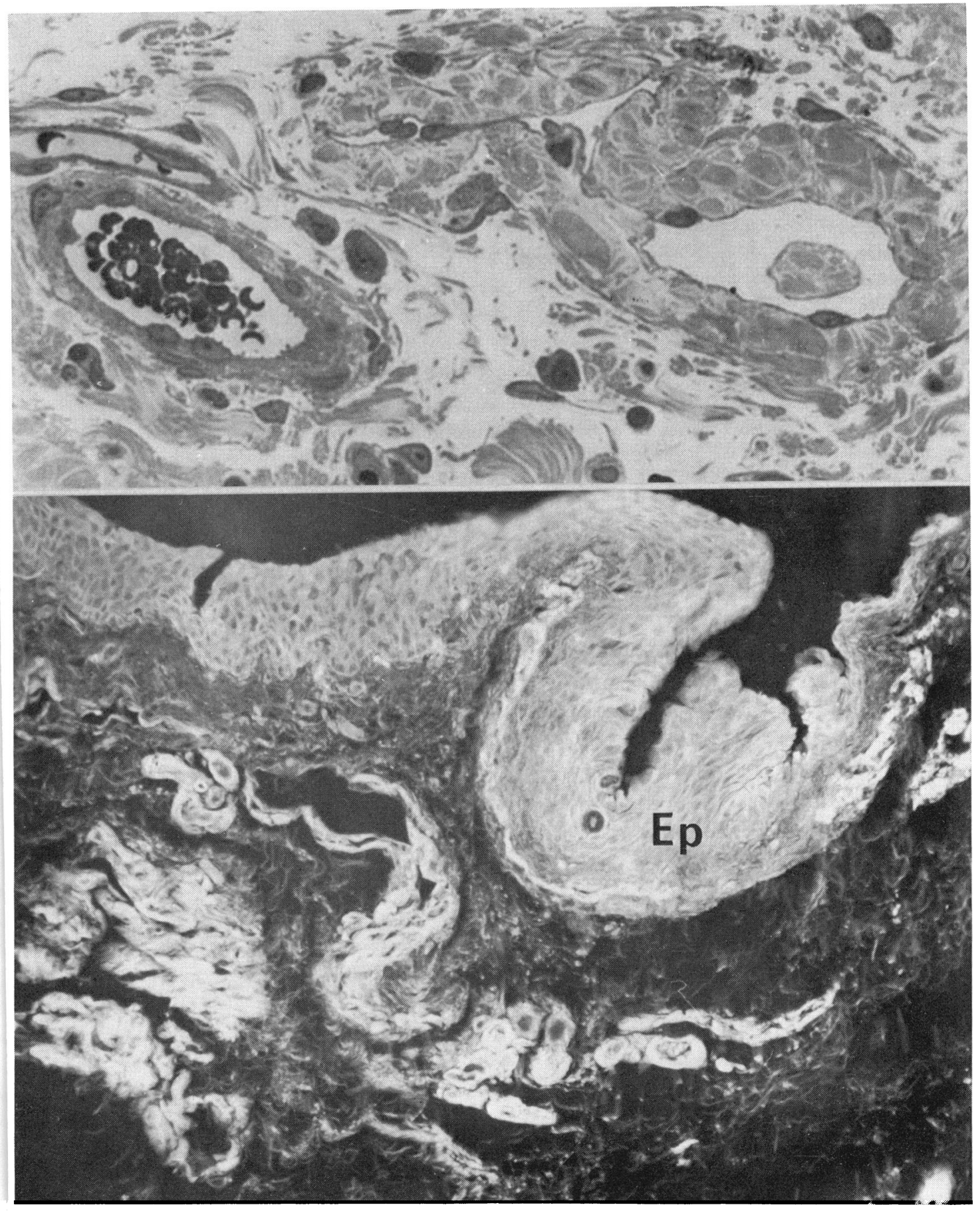

FIG. 6 (top) Light photomicrograph of conjunctival biopsy from Case I showing clumps of amorphous deposits around vessels. $\times 660$

FIG. 7 (bottom) Light photomicrograph of conjunctival biopsy from Case 2. Section was stained with thioflavine $T$ and viewed by ultraviolet light. Intensely fluorescent deposits are seen beneath conjunctival epithelium (Ep) and around blood vessels and lymphatics in conjunctival stroma. $\times 220$ 
showed the predominantly fibrillar nature of the material (Fig. II). The detailed morphology of the individual fibrils was similar to that described for the conjunctival deposits. No cells were seen in the sections examined.

\section{LENS}

Light microscopy of Case I showed a smooth posterior lens surface and the capsule appeared to be normal. Similarly, semi-thin Araldite sections of the lens from Case 2 showed a smooth posterior lens surface; there was no evidence of the remains of attachment of pseudopodia lentis seen clinically.

\section{Discussion}

A summary of cases with systemic amyloid disease and vitreous opacities reported in the literature is set out in the Table. Some cases have appeared in more than one report; we have included only the most recent report to allow a better appreciation of the long-term history of the disease. Most were proved cases of heredo-familial amyloidosis. A peripheral neuropathy was a common feature in affected families, but the incidence of vitreous opacities was reported less frequently.

Previously reported cases usually had a long history of visual loss before the correct diagnosis had been established (Table) and indeed in one case, there was no evidence of systemic disease at the time vitreous opacities were first noticed (Kaufman and Thomas, I959). Thus visual symptomatology could be the reason for initial presentation, as is also apparent from our patients. Loss of visual acuity in both eyes may not, however, be of equal duration and in a few reports, one eye was apparently normal at first examination (Schlesinger, Duggins, and Masucci, 1962; Andersson and Kassman, 1968).

The vitreous opacities characteristically had a linear structure, descriptions of 'sheet like', or 'band like' opacities being common (see Table). In those cases where the fundus could be seen, opacities were said to be in contact with the retina and retinal vessels through footplates (Falls, Jackson, Carey, Rukavina, and Block, I955; Wong and MacFarlane, 1967). Similar footplates were seen in the anterior vitreous in contact with the posterior lens surface (Falls and others, I955; Kaufman and Thomas, 1959). Vitreous opacities in contact with the posterior lens surface were noted in two cases described by Vogt (1942) although he did not suggest amyloidosis as being a cause; one of the patients had 'chronic tuberculosis'. The development of opacities in a previously clear vitreous was noted in one case (Andersson and Kassman, 1968), while a marked increase in the density of the opacities together with a reduction in visual acuity has been reported by several authors (Duke and Paton, 1965; Andersson and Kassman, 1968).

The clinical features of previously published cases are similar, suggesting that slowly progressive visual deterioration apparently caused by linear vitreous opacities with footplate attachments to the retina or posterior lens surface are diagnostic of amyloid disease.

Vitreous opacities in amyloid disease must not be confused with those resulting from more common causes-haemorrhage, inflammation, degeneration, or neoplasms. Opacities associated with amyloid disease may be uniocular, or asymmetric in the involvement of the two eyes. In addition, examination of the apparently normal eye has revealed perivascular greyish opacities on the retinal vessels (Schlesinger and others, 1962).

Pupillary abnormalities were a common ocular complication in many patients with vitreous opacities. The abnormalities were anisocoria, and the failure to react to light and accommodation. In addition a few cases had perivascular exudates; one was a histologically confirmed case of amyloid (Wong and MacFarlane, 1967), but another, of similar appearance, turned o dt to be a cytoid body (Crawford, 1967).

The diagnosis of systemic amyloidosis is usually confirmed by biopsy; skin, gingiva, rectum, liver, kidney, spleen, respiratory tract, and sternal puncture have all been used (Cohen, 1967). Ease of access and haemostasis have made the gingiva and rectum the two main sites. Positive biopsies for amyloid were obtained in 31 of 32 cases of systemic amyloidosis (Missmahl, 1968). The conjunctiva has not been considered a suitable site, perhaps because it retains normal appearance in systemic amyloidosis (Duke-Elder, 1965; Brownstein, Elliott, and Helwig, 1970). The positive conjunctival biopsies obtained in Cases $\mathrm{I}$ and 2, despite a normal clinical appearance of the conjunctiva, suggests that microscopic deposition of amyloid could frequently occur. The conjunctiva should be considered as a biopsy site for diagnostic confirmation of systemic amyloid disease (Tripathi and Ashton, 1976).

The origin of amyloid material in the body is not clear. Amyloid comprises three types of protein complexes, types $\mathrm{A}, \mathrm{B}$, and possibly $\mathrm{C}$ (Benditt, Erikson, Hermodson, and Ericsson, 1971). Type A is found in a perireticulin distribution, secondary to chronic sepsis or an inborn error of metabolism. Type B is mainly found in a pericollagen distribution secondary to myelomatosis and other paraprotein disorders, while Type $\mathrm{C}$ occurs with amyloid formed locally with certain tumours. Familial amyloid may involve either Type A or Type B (Hobbs, 1973). 


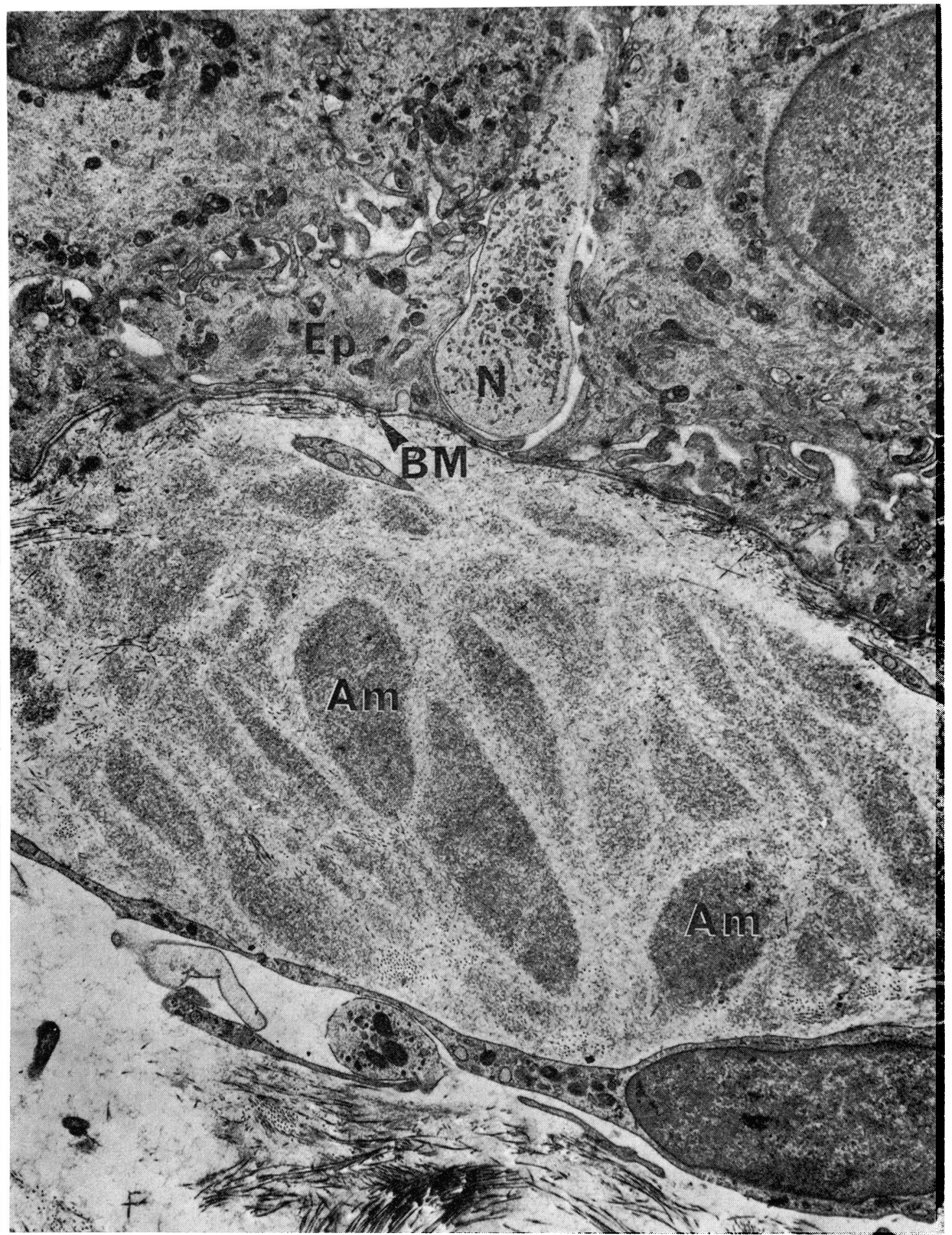

FIG. 8 Electron micrograph showing clumps of fine fibrillar deposits of amyloid (Am) beneath conjunctival epithelium (Ep). BM, intact basement membrane beneath conjunctival epithelium. $N$, nerve axon in conjunctival epithelium. $U A$ and $L C \times 125^{\circ}$ 


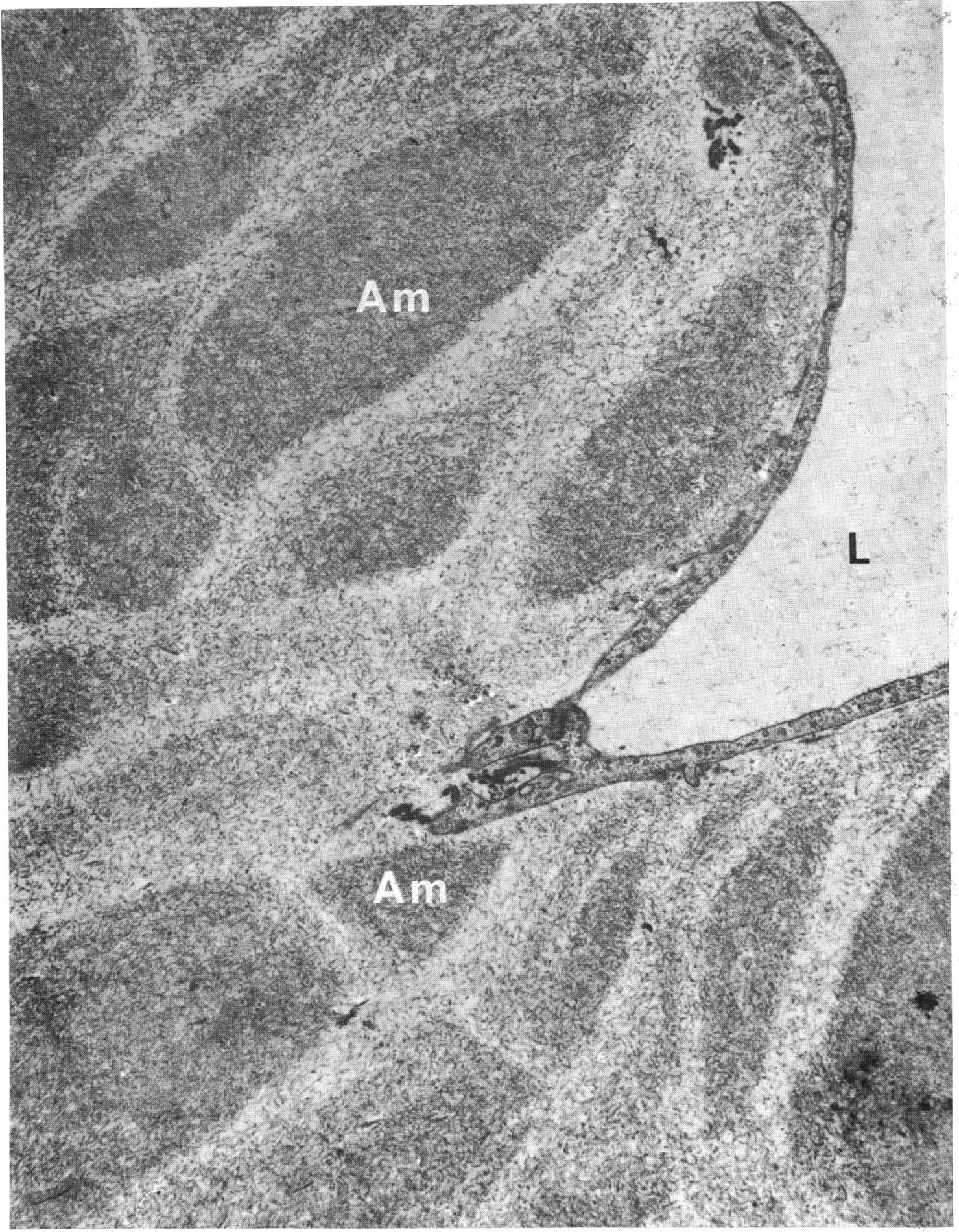

FIG. 9 Electron micrograph showing perilymphatic deposits of clumps of amyloid fibrils (Am). L, lumen of lymphatic. UA and LC $\times 15000$ 
Recent work on sequential amino-acid analysis suggests that amyloid-B is derived from part of a circulating immunoglobulin protein, itself derived from plasma cells (Glenner, Harbough, Ohms, Harada, and Cuetracas, 1970; Glenner, Terry, Harada, Isersky, and Page, 197I ; Glenner, Terry, and Isersky, 1973). In the case of occult or overt plasma cell dyscrasias, this protein appears to be the variable front-half of a light chain (the variable light portion) of an immunoglobulin. It has been suggested that phagocytic cells ingest this circulating protein and deposit amyloid fibrils (Glenner and others, 1973). In one series, 33 out of 40 patients with 'primary amyloid' were found to have malignant lymphoreticular disease (Hobbs, 1973).

Amyloid A protein has amino-acid sequences which are different from known immunoglobulin sequences. Neither their origin nor their precursor, however, is known (Hobbs, 1973).

The site of deposition of amyloid fibrils may depend on three main factors (Glenner and others, 1973). First, it depends on local variations in the rate of formation of the fibril precursor and its removal. Secondly, it depends on the nature of this precursor-for example, small molecules could penetrate capillary walls while larger ones precipitate in capillary lumens. In addition, its precursor may have relative tissue affinity (Ossermann, Takatsuku, and Talal, 1964). Thirdly, there may be a special relationship between the precursor synthesizing cell and the amyloid producing cell. The plasma cells producing a circulating precursor would give rise to systemic amyloid, while a localized plasma cell alone with adjacent histiocytes might produce localized amyloid deposits.

Systemic amyloid deposits secondary to an inflammatory process can resolve following removal of this process (Lowenstein and Gallo, I970; Hobbs, 1973). In primary amyloid disease the turnover rate would appear to be very slow, allowing accumulation of masses of amyloid material. Intravitreal amyloid deposits could occur after permeation of the precursor across the bloodaqueous barrier, to be converted possibly by intravitreal phagocytes into amyloid fibrils. The linear deposition of amyloid material may result from initial deposition around pre-existing collagen fibrils in the vitreous cavity.

The question arises why only a proportion of patients with systemic amyloid disease develop vitreous opacities. This may be due to one of several factors. All patients may develop opacities in time or, since the disease has a poor prognosis, the patient may succumb from renal or cardiac complications before ophthalmic complications become manifest. There may be variations in the chemical composition of the amyloid protein or in its circulating precursor from case to case. Finally, local factors, such as the state of the intravitreal collagen framework, or the presence of phagocytic cells in the vitreous cavity, may also play an important role.

There is no known treatment for primary amyloid disease. Possible therapeutic attacks could be against the precursor secreting cell, the circulating immunoglobulin, or the amyloid material (Glenner and others, 1973). Cases where plasma cell abnormalities can be demonstrated could be attacked with immunosuppressive drugs and this has been tried with variable results (Missmahl, 1968; Barth, Willerson, Waldmann, and Decker, I 969; Jones, Hilton, and Hobbs, 1972). Immunoabsorbents against the circulating immunoglobulin are a possibility (Glenner and others, 1973). The mobilization of amyloid deposits that occurs after removal of the stimulus shows that the fibril deposition is not irreversible, and a possible method of attack has been suggested by the demonstration that phagocytosis of amyloid fibrils occurred after treatment of the fibrils with specific antisera (Zucker-Franklin, 1970).

Finally, the direct surgical approach has been tried, and there have been several reports of vitrectomy (Duke and Paton, 1965; Kasner and others, I968). Our experience in Case I suggested that despite removal of amyloid material, the opacities returned after several months: thus removal of opacities is not equivalent to cure; in any case these patients have a poor prognosis as is apparent from many reported cases, and this fact must be borne in mind when contemplating major ophthalmic surgery.

\section{Summary}

Three patients who initially presented to the ophthalmologist with a history of gradual deterioration of visual acuity showed, on biomicroscopic examination, a linear meshwork of opacities in the vitreous attached to the posterior surface of the lens in the form of pseudopodia lentis. Amyloidosis of the vitreous associated with systemic amyloid disease was diagnosed because of the characteristic nature of the opacities. This was confirmed initially in two of the cases by light and electron microscopical examination of a biopsy of the clinically normal conjunctiva, subsequently by systemic investigations, and finally, by direct histochemical and elecron microscopical examination of the vitreous which became available after vitrectomy in all three cases. It was not possible to examine other members of the families. The relevant literature on vitreous amyloidosis is reviewed in relation to our own findings and the importance of a diagnostic conjunctival biopsy is emphasized. This paper is the first British report on primary vitreous amyloidosis. The pathogenesis of vitreous amyloid opacities is 


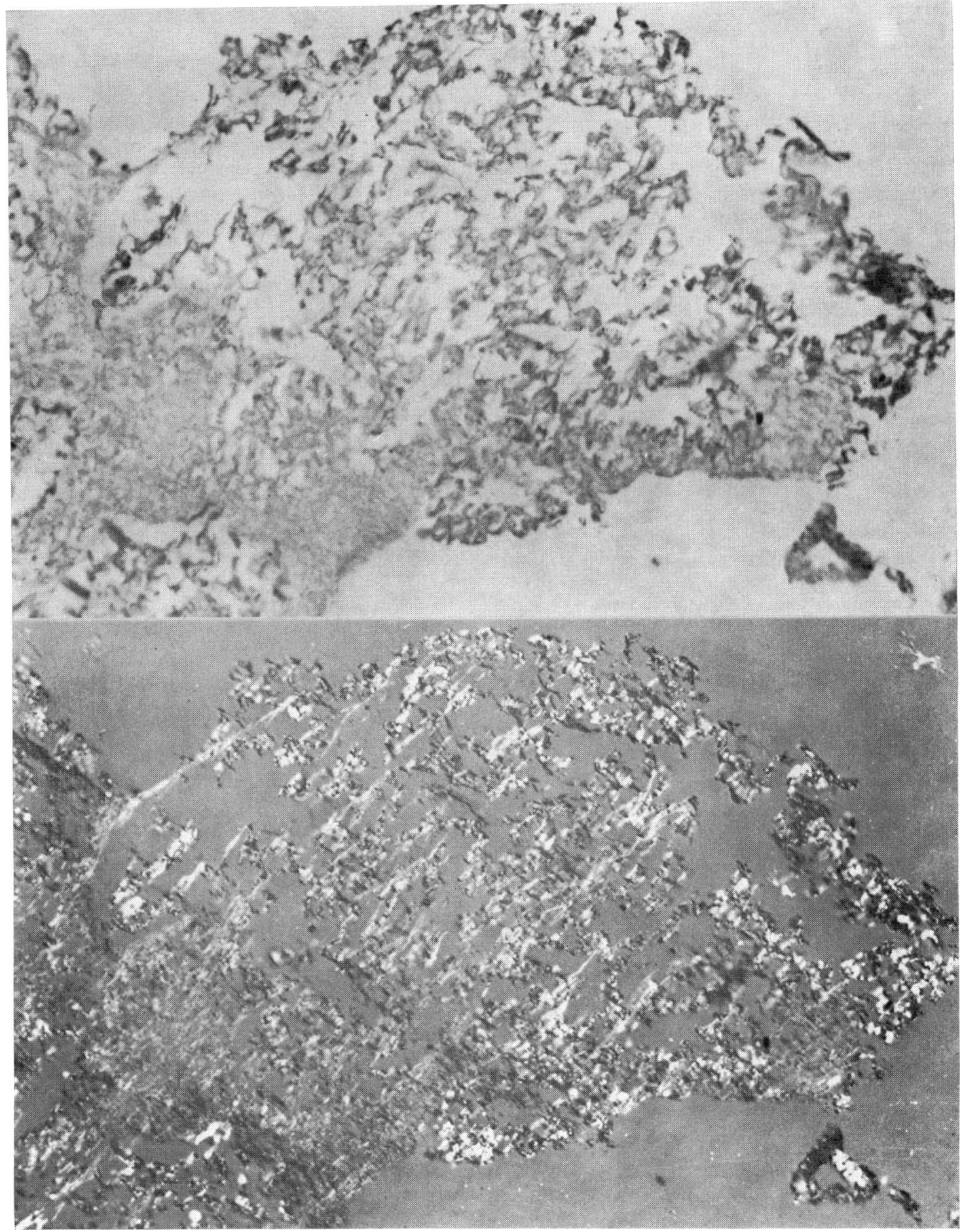

FIG. Io Light photomicrograph of vitreous smear stained with congo red; (a, top) viewed by ordinary light and (b, bottom) viewed by polarized light which reveals green dichroism and birefringent nature of the material. $\times 200$ 


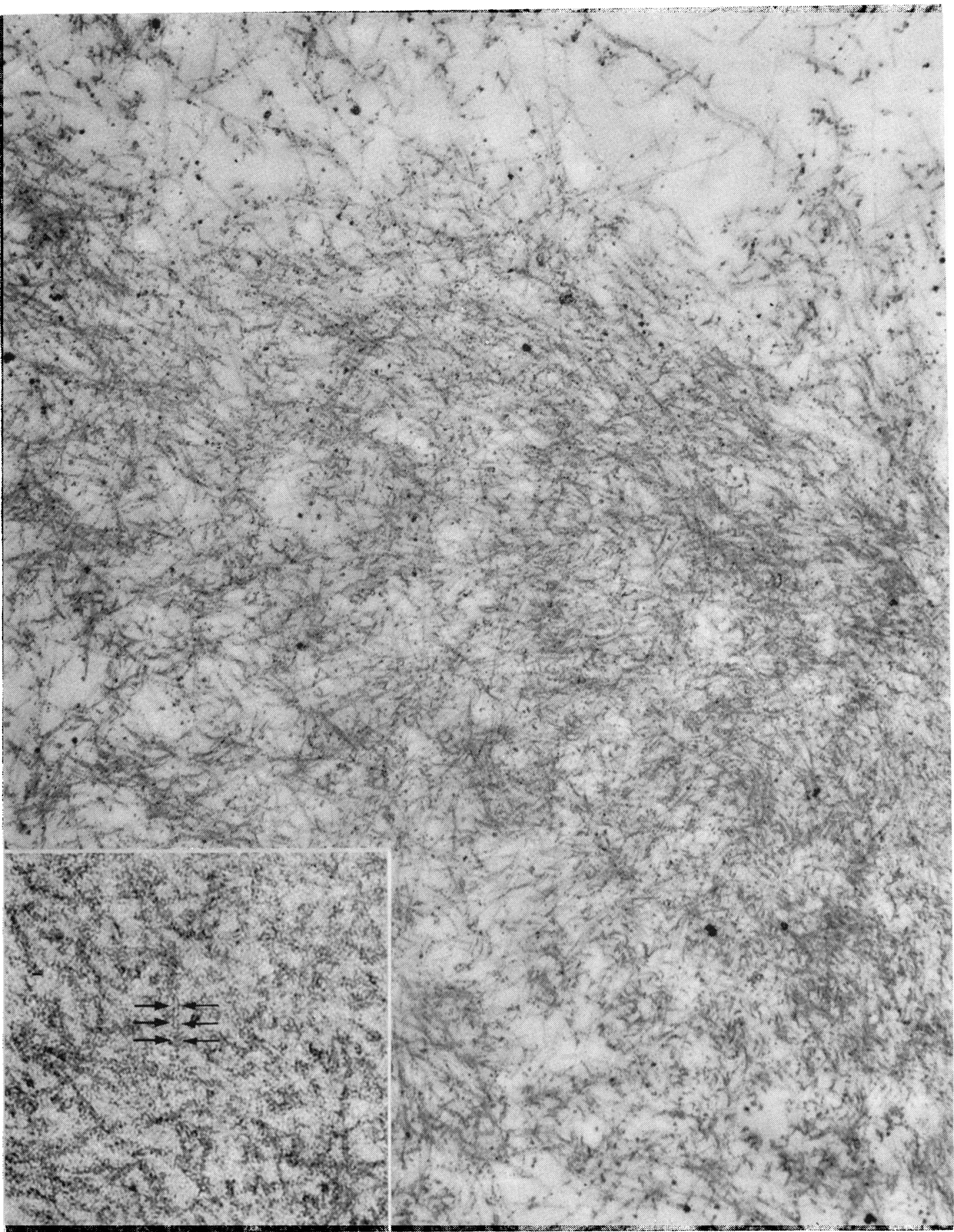

FIG. I I Electron micrograph of the vitreous deposits showing fine fibrillar nature of amyloid material. $U A$ and $L C \times 50000$.

Inset: Amyloid fibrils at higher magnification. Individual fibrils have beaded profile and appear to be composed of two laterally-aligned filaments (arrows). UA and LC $\times 140000$ 
discussed in the light of current concepts of amyloidosis. Since the vitreous opacities due to amyloid deposits appear to be one of the manifestations of systemic amyloid disease, surgical removal of the opacities by vitrectomy may not produce longlasting results. Moreover, in contemplating surgical treatment the ophthalmologist should bear in mind the poor prognosis of systemic amyloidosis.
We thank Mr R. K. Blach for his encouragement and을 permission to publish details of Cases I and 2, Mr Frank $\Rightarrow$ Law for permission to publish an account of Case $3, \stackrel{5}{+}$ and $\mathrm{Mr} \mathrm{N}$. Brown for help in microphotography. Technical assistance was provided by Mrs T. Brittain,을 Mr R. Alexander, and Mr R. Howes, and secretarialo assistance by Miss C. Wilson and Mrs S. Bird. This $\mathbb{D}$ work was supported in part by the Locally Organized Clinical Research Scheme of Moorfields Eye Hospital. o

\section{References}

ANDERSSON, R., and KASSMAN, T. (i968) Acta ophthal. (Kbh.), 46, 44I

Barth, W. F., Willerson, J. T., WAldMANN, T. A., and DeCKer, J. L. (1969) Amer. $\mathcal{F}$. Med., 47, 259

BENDITT, E. P., ERIKSON, N., HERMODSON, M. A., and ERICSSON, L. (I97I) Federation of European Biochemical

Societies Letters, vol. 19, p. 169 (cited by J. R. Hobbs (1973) Proc. roy. Soc. Med., 66, 705)

BOERE, H., RUINEN, L., and SCHOLTEN, J. H. (1965) F. Lab. clin. Med., 66, 943

Brownstein, M. H., Elliott, R., and helwig, e. B. (1970) Amer. F. Ophthal., 69, 423

CHAMBERS, R. A., MEDD, W. F., and SPENCER, H. (1958) Quart. F. Med., 27, 207

COHEN, A. s. (1967) New Engl. F. Med., 277, 522

COOPER, J. H. (1969) $\mathcal{F}$. clin. Path., 22, 410

CRAWFORD, J. B. (1967) Arch. Ophthal., 78, 218

DELANK, H. W., KOCH, G., KÖNN, G., MISSMAHL, P., and SKWELACK, K. (1965) Arzneimittel-Forsch., I9, 40I

DUKE, J. R., and Paton, D. (1965) Trans. Amer. ophthal. Soc., 63, 146

DUKE-ELDER, S. (1965) 'System of Ophthalmology', vol. VIII, pt. I, p. 587. Kimpton, London (1969) Ibid., vol. XI. Kimpton, London

FAlls, H. F., JaCkson, J., CARey, J. H., Rukavina, J. G., and Block, w. D. (I955) Arch. Ophthal., 54, 660

GLENNER, G. G., HARBoUgh, J., OHMS, J. L., hARAdA, M., and Cuetracas, P. (1970) Biochem. biophys. Res. Commun., 4I, 1287

, TERRY, W. D., HARADA, M., ISERSKy, C., and PAGE, D. (197I) Science, I7I, I 150

$\longrightarrow,-$, and ISERSKY, C. (I973) Semin. Hemat., Io, 65

GUEFT, B., KIKKAWA, Y., and HIRSCHL, S. (1968) In 'Amyloidosis: Proceedings of Symposium', pp. I72-183.

University of Groningen, Netherlands

HAMBERG, A. (1971) Ophthalmologica (Basel), r62, 173

HobBs, J. R. (I973) Proc. roy. Soc. Med., 66, 705

JAFFE, N. S. (1969) 'The Vitreous in Clinical Ophthalmology'. Mosby, St Louis

JONES, N. F., HILTON, P. J., and HOBBS, J. R. (1972) Lancet, 2, 6 I 6

Kantarjian, A. D., and de Jong, R. D. (1953) Neurology (Minneap.), 3, 399

Kasner, D., Miller, C., Taylor, W. H., LEVer, R. J., and Norton, w. D. (1968) Trans. Amer. Acad. Ophthal.

Otolaryng., 72, 410

KaUfman, H. E. (1958) Arch. Ophthal., 60, 1036 , and THOMAS, L. B. (1959) New Engl. F. Med., 26r, 1267

LAW, F. (197I) Trans. ophthal. Soc. U.K., 81, I73

LOWENSTEIN, J., and Gallo, G. (1970) New Engl. F. Med., 282, 128

MISSMAHL, H. P. (1957) Technik, 63, I 33

(1968) In 'Amyloidosis: Proceedings of Symposium', p. 429. University of Groningen, Netherlands ossermann, e. F., takatsuku, K., and talal, N. (1964) Semin. Hemat., 1, 3

PEARSE, A. G. E. (1972) 'Histochemistry ('Theoretical and Applied)'. Livingstone Churchill, London

PUCHTLER, J. SWEAT, F., and LEVENE, M. (I962) F. Histochem. Cytochem., ro, 355

SCHLESINGER, A. S., DUGGINS, v. G., and MASUCCI, E. F. (I962) Brain, 85, 357

SHIRAHAMA, T., and CoHEN, A. S. (1965) Nature (Lond.), 206, 737

$\longrightarrow$, and (1967) F. Cell Biol., 33, 679

SORENSON, G. D., and FINKe, E. (1968) In 'Amyloidosis, Proceedings of Symposium', pp. I84-I93. University of

Groningen, Netherlands

TRIPAThI, R., and AShton, N. (1976) In 'Birth Defects: Original Article Series', ed. E. Cotlier and A. Bron.

National Foundation-March of Dimes. Liss, New York. (In press)

vassar, P. s., and culling, c. F. A. (1959) Arch. Path., 68, 487

VOGT, A. (1942) 'An Atlas of Slit Lamp Microscopy', vol. III, p. I000. Enke, Stuttgart

WONG, v. G., and MACFARLANE, D. F. (1967) Arch. Ophthal., 78, 208

ZUCKER-FRANKLIN, D. (1970) F. Ultrastruct. Res., 32, 247 